\title{
Os sinais da educação integral (1960)
}

\author{
Signs of integral education (1960)
}

Edilson de Souza*

Universidade Federal de Santa Maria

Resumo Nesta tentativa de aproximar Anísio Teixeira e Darcy Ribeiro trilhamos pela temática da educação integral, condição primordial para um projeto de emancipação social. Orientando-nos por uma "política de liberdade", fizemos com que esses dois intelectuais cruzassem novamente um o caminho do outro. Para nós, os resultados foram férteis, porque ao olharmos tanto para a trajetória quanto para seus projetos, conseguimos vislumbrar a possibilidade de uma sociedade autônoma alinhada a um projeto pensado por um, para atender a uma sociedade em pleno processo de crescimento, que ia deixando um lastro de pessoas desatendidas pela escola, e pelo outro, para resgatar o direito social, perdido ao longo da história republicana do pais.

Palavras-chave: Escola Classe/Escola Parque; Anísio Teixeira; Darcy Ribeiro; Centros Integrados de Educação Pública (CIEPs).

Abstract In this attempt to approach Anísio Teixeira and Darcy Ribeiro we tread by the integral educationtheme, primary condition for a social emancipation project. Guiding us through a "free policy", we made that these two intellectual crossed again one the path of another. For us, the results were fertile, because when we look at both the history and for their projects, we see the possibility of an autonomous society aligned with a thought for a project to meet a society in the process of growth, which was leaving a ballast of people neglected by the school, and on the other, to rescue the social right, lost throughout the republican history of the country.

KEYWORDS: School Class / School Park; Anísio Teixeira; Darcy Ribeiro; Integrated Centers for Public Education (CIEP). 


\section{Caminhos Cruzados de Anísio e Darcy}

Nossa tentativa de aproximar Anísio Teixeira e Darcy Ribeiro segue pela temática da educação integral por esse texto, apresentamos uma relação de cumplicidade entre ambos, demonstrada pelo projeto de emancipação social, apontando a possibilidade da construção de uma sociedade autônoma, alinhada a um projeto educacional de nação, não só pelo envolvimento político e social, mas também pelo trabalho que desenvolveram e através dos escritos que deixaram, neste texto, não é nossa intenção fazer um estudo a partir das correspondências trocadas entre eles, mas usa-las como recurso bibliográfico para mostrar que o comprometimento com o desenvolvimento do país era preocupação reciproca, iniciaremos essa aproximação com, por exemplo, essa correspondência datada de 28 de março de 1966, demonstrando seus compromissos com a escola pública e com o povo:

... respondo a isto e a perplexidade e poderia cair com a crença de que nos cabe a nós, a intelectualidade dos povos morenos e pobres, a função de nos fazermos um novo sal da terra. Tendo tarefas específicas de luta contra o atraso e a miséria que nos aqueceram o peito por décadas, nós, os deserdados e discriminados que não possuímos bombas temos uma autoridade moral de importância decisiva neste mundo em crise de valores. [...] Por que o senhor não escreve uma carta de pito geral ecumênica. Fale em nome de W. James, de Dewey aos yanques. [...] E fale como caboclo do sertão sanfranciscano, último reduto de romanidade (RIBEIRO, Darcy. Carta a Anísio Teixeira. S.1., 28 mar. 1966.).

A questão central é a indignação, já que, tomado pela incerteza dos rumos que o país estava tomando, sendo pautado pelas organizações mundiais nos planos econômico, político, social, cultural e, principalmente, educacional, Darcy vai a Anísio e o chama ao debate para discutir as questões educacionais, um debate franco, necessariamente republicano, onde Darcy assume Anísio como mentor:

...se me perguntassem pelo encôntro mais importante de minha vida, eu diria que foi o nosso encontro. O senhor não avaliará o quanto eu the devo e como sou consciente de que em educação nada mais fiz do que pôr meu dínamo de agitação, zumbindo em tôrno de suas idéias (RIBEIRO, Darcy. Carta a Anísio Teixeira, S.1., 11 nov. 1964.).

A história revela que Darcy seguiu à risca suas convicções, fazendo com que sua vida como intelectual fosse a busca utópica de uma sociedade melhor, tendo os processos educacionais como centralidade. Darcy Ribeiro junta sua prática ao pensamento anisiano para desenvolver os projetos e programas que o "pioneiro" mantinha em pauta desde a década de 1920, fazendo com que desse encontro a paixão reformadora fosse animada pela defesa da escola pública.

Havia uma diferença básica entre mim e o Anísio: ele confiava muito na educação comunitária; eu dizia: Anísio, isso é loucura, o nos Estados Unidos é comunitária porque é educação é luterana. O luterano decidiu que a melhor forma de rezar era ler a Bíblia. Então a educação era comunitária por haver uma comunidade religiosa que 
queria manter a sua escola e aqui não há isso. Essa canalha que não quer educar ninguém. Eu era federalista e o Anísio era municipalista e comunitarista como educador. (ROCHA, 2002, p. 65).

No entanto, os dois se diferenciavam em relação ao conceito de sociedade. Anísio, liberal, pressupunha como visão de mundo o posicionamento consciente do homem, que, na sociedade urbana, precisava ser preparado intelectualmente para compreender a realidade social.

Contudo, Darcy Ribeiro como um radical (socialista) usava sua inquietude como impulso para entender os dilemas de uma sociedade excludente, onde conviviam contradições agudas que evidenciavam o fracasso da democracia, a violência autoritária, o atraso não apenas econômico-tecnológico e, principalmente, a educação terceiro mundista.

Darcy Ribeiro foi um intelectual dos anos 1950. Ao menos as questões que o mobilizaram são mais bem compreendidas no marco daquela geração. A geração de 50 foi uma geração que teve a crença na capacidade de intervenção planejada, racional e, em alguns casos, engajada, dos intelectuais com vistas à modernização do país - uma geração intelectual profundamente marcada pela Sociologia, pelos temas e problemas tratados e eleitos por esse campo de conhecimento. A própria disciplina se apresentava em seu sentido de missão transformadora, racionalista e universalizante. Mas, sobretudo pelo cruzamento sugerido de pensamento e ação combinados sob o manto do conhecimento científico e da proposição política. (BOMENY, 2009, p. 111).

Anísio Teixeira tinha a compreensão de que a escola deveria ser o espaço destinado à formação universal do indivíduo vinculado à própria vida, e não a mera preparação para a vida. Nesse sentido, o projeto e a construção escolar deveriam obedecer ao princípio da dignidade, a mesma dignidade da vida, um direito a ser assegurado a todos pela democracia. Democracia que ele definia a partir da exigência de que a educação fosse garantida como o primeiro de todos os direitos, em nome da igualdade de oportunidades.

Obrigatória, gratuita e universal, a educação só poderia ser ministrada pelo Estado. Impossível deixá-la confiada a particulares, pois êetes somente podiam oferecê-la aos que tivessem posses (ou a "protegidos") e daí operar antes para perpetuar as desigualdades sociais, que para removê-las. A escola pública, comum a todos, não seria, assim, o instrumento de benevolência de uma classe dominante, tomada de generosidade ou de medo, mas um direito do povo. Sobretudo das classes trabalhadoras, para que na ordem capitalista, o trabalho (não se trata, com efeito, de nenhuma doutrina socialista, mas do melhor capitalismo) não se conservasse servil, submetido e degradado, mas, igual ao capital na consciência de suas reivindicações e dos seus direitos (TEIXEIRA, 1956. p. 6).

Nesse sentido, o educador contribuiu com um lastro inovador, materializado desde o tempo em que fora Diretor da Instrução, de 1924 a 1929, na Bahia. Seu legado aponta para uma sociedade efetivamente democrática, o que só se torna possível com uma escola pública, laica, gratuita e republicana. 
Portanto, a compreensão do intelectual como o indivíduo caracterizado por uma atitude crítica permanente, refletida na produção e divulgação de seus ideais, não se afasta substancialmente daquela apresentada por Sirinelli (1996), que concebe a noção de intelectual e desde uma "geometria variável", mas baseada em invariantes. Noção que poderia desembocar em duas acepções do termo intelectual: uma ampla e sociocultural, na qual estariam compreendidos os criadores e os "mediadores" culturais; e outra, mais estreita, baseada na ideia de engajamento.

No contexto da escrita historiográfica,

Entre o coro dos intelectuais e a peça cheia de 'clamor de fúria' que é representada na rente do palco, urdiram-se relações complexas, cuja observação toca o âmago do político e faz, portanto, dessa história dos intelectuais uma história a seguir, em todos os sentidos do termo. (SIRINELLI, 1996, p. 262).

Tanto para a trajetória de Darcy Ribeiro, quanto para a de Anísio Teixeira, em ambos, o compromisso com a produção de conhecimento estabeleceu relações com a transformação da sociedade, sendo esses traços constantes em suas obras.

Para além dessa abordagem da história dos intelectuais, Jacoby (2001) demonstra uma preocupação que configuraria um novo tipo de intelectualidade em relação à tratada por Le Goff (1984), surgida mais recentemente, ainda no começo do séc. XIX, na Europa e na Rússia.

A participação orgânica em ações sociais foi sempre o ponto norteador, fazendo com que a vida intelectual fosse uma missão orientada pela constante responsabilidade de transformação social que eles assumiram. Uma função crítica da ordem, bem como os traços de coerência entre obra e vida - coerência política entre teoria e práxis, orientadas por um projeto deliberado.

\section{Direito à Educação - uma discussão em aberto}

Educação em tempo integral ${ }^{1}$ - de acordo a LDB/1996, em seu artigo 34, (parágrafo segundo) é definida como "a jornada escolar no ensino fundamental que incluirá pelo menos quatro horas de trabalho efetivo em sala de aula, sendo progressivamente ampliado o período de permanência na escola. [...] O ensino fundamental será ministrado progressivamente em tempo integral, a critério dos sistemas de ensino".

Numa interpretação superficial da Lei, entende-se que educação em tempo integral implica na ampliação da jornada escolar, onde o espaço da escola se amplia nesse tempo. $\mathrm{Na}$ prática, e apresentado em estudos feitos pela $\mathrm{UNIRIO}^{2}$ Intitulado "Mapeamento das experiências de jornada escolar ampliada no Brasil: Estudo Qualitativo" de 2012, a referida pesquisa apontam que o entendimento acerca de Educação Integral, não significa o aumento do tempo em que os estudantes ficam na escola ou estão ocupados com atividades extracurriculares, orientadas pelos professores, mas sim ao aumento do tempo. Muitos municípios conclamam estarem investindo na educação integral, sem perceberem que estão apenas ampliando o tempo escolar. Não sendo possível ainda analisar resultados em termos qualitativos, pois muitas escolas não cria- 
ram mecanismos para avaliar os resultados efetivos na formação ética, moral, política, sociocultural e espiritual, mantendo uma confusão pedagógica entre educação integral e educação apenas em tempo integral.

A educação integral se constitui pela jornada ampliada ou escolar de tempo integral, compreendendo-a como ampliação da educação convencional, a qual a carga horária diária escolar é de quatro horas. Há várias décadas, a jornada ampliada se consolidou como elemento qualificador de propostas educacionais, fazendo com que o tempo se tornasse a principal condição para que o processo educacional fosse entendido como educação integral.

Nesse sentido, escolarizar-se era sinônimo de permanência na instituição educacional durante o dia inteiro e durante muitos anos, ganhando um novo sentido após as reformas educacionais a partir da década de 1920. Em especial no Estado de São Paulo, com Sampaio Dória, sendo as discussões em torno do tempo escolar consolidadas na década de 1930, impulsionadas pelas reformas paulistas da década de 1920 .

$\mathrm{Na}$ tentativa de atender mais pessoas sem alterar a estrutura educacional, o Brasil inaugura um novo período de organização escolar, qual seja, a compactação da escola em seu tempo e organização, institucionalizando a escola de turnos nas décadas posteriores para atender às demandas de uma sociedade em expansão que exigia a escolaridade básica para todos.

O país passou por mudanças decisivas, que começam na proclamação da República, em 1889, e chegam a 1920, estimuladas pelas revoluções burguesas ${ }^{3}$ em seus ideais de igualdade e oportunidade entre as pessoas, mudando a capacidade individual de decisão sobre a aceitação ou não de tais liberdades.

A possibilidade de mudança educacional só veio a materialização do pensamento de Anísio Teixeira no Centro Educacional Carneiro Ribeiro, em Salvador no período em que foi secretário da Educação e Saúde da capital baiana e anos depois quando Diretor do INEP na construção da Escola-Parque de Brasília.

A Escola-Parque de Salvador, inaugurada em 1950 pelo Anísio, parte integrante do conjunto denominado Centro de Educação Carneiro Ribeiro, é, realmente, uma escola de tempo integral, porque o menino passa de 4 a 5 horas na escola, antes depois das aulas. (ROCHA, 2002, p. 67).

Ao mesmo tempo, a filosofia de John Dewey acompanhou Anísio Teixeira sendo interpretada e assimilada para a "reconstrução educacional no Brasil". Para o educador baiano, a democracia está associada a um sistema educativo forte e eficaz, em que a cultura intelectual, social, artística e vocacional seriam os aspectos fundamentais. Dessa forma, a Escola-Parque de Brasília seria a culminação dos pensamentos de Anísio desde as décadas de 1920, sendo aplicados os ideais da Educação Nova, na forma de um novo currículo, de um novo programa e também de um novo professor.

O trabalho de Anísio desvela algumas contradições no entendimento atual sobre educação integral e escola de tempo integral. Embora a escola de tempo integral 
ofereça, em princípio, melhores condições para o desenvolvimento da educação integral, não se pode confundir essas duas noções. Trata-se de uma decisão política e que deve ser definida claramente no projeto político-pedagógico da escola.

$\mathrm{Na}$ concepção de Cavaliere (2002), enquanto a escola se destinava efetivamente a poucos, alcançando pequena parcela da população e tendo como principal função a instrução escolar, sua ação social era uma expansão linear dos processos integradores da comunidade sociocultural homogênea, que a ela tinha acesso. A partir do momento que o processo de escolarização atingiu as grandes massas da população brasileira, fato que se deu na segunda metade do século XX, o panorama educacional se modifica.

Diante desse cenário, sistemas educacionais das diversas esferas representativas no Brasil investem em projetos no setor público de educação fundamental, que se caracterizam pela ampliação da jornada escolar diária do estudante na escola, com o intuito de atender não somente às necessidades cognitivas, mas também a seus aspectos sociais e afetivos.

Calefi (2003), por outro lado, constata que a ampliação do tempo no campo legal, para atender ao ambiente educacional, passa a ser peça fundamental e estruturadora das necessidades de cada momento. Tentando, assim, equilibrar as forças políticas e as forças sociais, mesmo que esse ideal não seja exitoso.

O processo de ensino não depende necessariamente do espaço circunscrito ao lócus escolar, uma vez que a aquisição de conhecimento é passível de acontecer na medida em que os sujeitos movimentam-se na direção do conhecimento ou a partir de espaços de socialização. Contudo, o conhecimento formal e sistematizado cabe ao lugar que denominamos escola.

\section{A gênese da concepção de Educação Integral no Brasil}

O Centro Educacional Carneiro Ribeiro foi inaugurado no dia 21 de outubro de 1950, na Bahia, surgindo como uma proposta inovadora que contemplava em sua organização o horário integral e, na proposta pedagógica, o respeito à cultura do aluno. A organização das turmas era realizada pela idade cronológica, distintamente à da matrícula por série, utilizada no sistema de ensino daquela época.

O Centro Educacional Carneiro Ribeiro, promotor de uma educação primária integral e tributário de uma concepção de educação escolar pela experiência e pelas vivências culturais, construída no bairro da Liberdade na Bahia, concentrava uma população em situação de extrema pobreza. No discurso de inauguração, Anísio Teixeira explicita o que chamou de deterioração da escola primária.

Anísio concebia a Escola Parque como "um ensaio de solução para a educação primária” (TEIXEIRA 1962, p. 25). Ao propor um modelo para a educação nacional que não pretendia ser um mero "remédio circunstancial", compreendia que o acelerado desenvolvimento econômico formava uma nova sociedade, que precisava ser atendida. Logo a educação primária no País demandava mudanças estruturais, 
enquanto uma instituição fundamental para a sociedade em fase de transformação (TEIXEIRA 1959, p.80).

A estrutura de funcionamento do CECR consistia em quatro escolas-classe para uma escola-parque, atendendo cerca de 4000 alunos, com idade entre 7 a 15 anos, que permaneciam no centro das $7 \mathrm{~h} 30 \mathrm{~min}$ às $16 \mathrm{~h} 30 \mathrm{~min}$.

As escolas-classe contavam com 12 salas de aula, áreas cobertas, gabinetes médicos e dentários, salas administrativas, jardins, hortas e áreas recreativas. Os alunos permaneciam 4 horas na escola, desenvolvendo estudos escolares através das disciplinas: linguagem, aritmética, ciências e estudos sociais. Após os alunos passarem a manhã na escola-classe, encaminhavam-se para a Escola Parque, onde passavam mais quatro horas, completando o tempo integral com atividades nos diversos setores.

O ensino era diversificado em grupos e por centros de interesses ou unidades de trabalho, nas classes experimentais. As atividades eram organizadas pelos alunos: correios, clubes, biblioteca, banco, lojas, rádio escola etc. Pesquisas e excursões incentivavam a investigação dos aspectos estudados. Outras atividades extra-classe chegaram a ser desenvolvidas, como o escotismo, as campanhas para a melhoria do aprendizado, a Associação de Pais e Mestres (ÉBOLI 1969).

Nas escolas-classe, era desenvolvido o ensino de letras e ciências e nas escolas-parque estavam distribuídas as atividades sociais e artísticas, as de iniciação ao trabalho e educação física. As atividades desenvolvidas na escola-parque, que contava com uma área de $42.292 \mathrm{~m} 2$, arborizada e gramada, complementavam de forma alternada o horário das escolas-classe e, assim, o aluno passava o dia todo no Complexo, onde também se alimentava e tomava banho. Também estava prevista a construção de residências para $5 \%$ do total das crianças da escola que fossem identificadas como abandonadas, como destaca Éboli (1969).

Em 1964, a obra foi dada como terminada com a construção da escola-classe 4 , apesar de faltar construir-se a residência destinada a 5\% do total das crianças, reconhecidamente abandonadas, que deveriam aí viver como se fosse a sua própria casa. O Centro Educacional Carneiro Ribeiro tem 4 Escolas-Classe e uma Escola-Parque, num total de 11 prédios, e ocupa grande área do bairro da Liberdade. Esta escola está localizada no meio das outras unidades, num raio aproximado de $1,5 \mathrm{~km}$. (ÉBOLI 1969 p. 20).

Os objetivos da proposta do Centro Carneiro Ribeiro revelavam os pressupostos da obra teórica e prática de Anísio Teixeira, como enfatiza Éboli (1969):

a) dar aos alunos a oportunidade de maior integração na comunidade escolar, ao realizar atividades que os levam à comunicação com todos os colegas ou com a maioria deles;

b) torná-los conscientes de seus direitos e deveres, preparando-os para atuar como simples cidadãos ou líderes, mas sempre como agentes do progresso social e econômico; 
c) desenvolver nos alunos a autonomia, a iniciativa, a responsabilidade, a cooperação, a honestidade, o respeito a si mesmo e aos outros $(1969$, p. 20).

Teixeira visava construir nove Centros, de modo que pudesse ser efetivado aquilo que ele denominou de uma "pequena universidade infantil", oferecendo às crianças uma convivência que retratasse a vida em sociedade.

\begin{abstract}
Um muro branco e simples, como de qualquer casa, separa o mundo da Escola-Parque do mundo cá de fora. Quem passa pela rua Saldanha Marinho, no bairro popular da Caixa Dágua, não imagina que atrás daquele despretensioso portão existe uma escola que, em seu conjunto, lembra "uma pequena universidade infantil". Só penetrando nela e aí permanecendo algum tempo é que se poderá compreender sua significação para aquêles meninos alegres e desinibidos que se movimentam de um setor para outro, com seus uniformes azuis! (ÉBOLI, 1969, p. 35).
\end{abstract}

O projeto recebeu grande divulgação nacional e internacional, os aspectos arquitetônicos e pedagógicos foram motivo de elogios de organismos internacionais, como ressalta Almeida (2001). Porém, sofreu também críticas, como a denúncia das condições precárias em que se encontravam as demais escolas do Estado.

A experiência do Centro Educacional Carneiro Ribeiro é analisada em seu livro Educação não é privilégio (TEIXEIRA, 1994), justificando a necessidade de a escola acompanhar o desenvolvimento científico, possibilitando uma ação pratica do conhecimento teórico.

No entanto, a concepção de escola, tão sonhada por Anísio, em condições de igualdade, sofreu descaso público, bem como falta de recursos para sua concretização, no que diz respeito à construção da residência para os alunos reconhecidamente abandonados.

\title{
As Escolas-Classe/Parque de Brasília: uma experiência outra
}

Dez anos depois, na década de 1960, em Brasília, uma nova experiência de escola pública de tempo integral, no governo de Juscelino Kubitschek, assinala rumos pioneiros para as políticas sociais brasileiras e, dentre elas, as educacionais. Assim, em 21 de abril de 1960, no Distrito Federal, o complexo Escola Classe/Parque é inaugurado, estabelecendo a escola pública sonhada por Anísio Teixeira.

A primeira Escola Parque de Brasília está situada na entre-quadra 307/308 Sul, no Plano Piloto. Seu projeto arquitetônico é de autoria do arquiteto José Reis, integrante da equipe de Oscar Niemayer, e foi concebido com base no ordenamento urbanístico do Plano Piloto, proposto por Lúcio Costa. O princípio básico da organização da cidade é o das "Unidades de Vizinhança", formadas pelo agrupamento de superquadras, de quatro em quatro, e compreendem, além dos blocos residenciais, todos os equipamentos necessários para a vida em comunidade: o comércio local, a igreja, o clube, o cinema, a biblioteca, o posto de saúde, a delegacia de polícia, correios e outras facilidades colocadas à disposição dos seus habitantes. 
As Escolas-Classe e Escolas-Parque, na cidade de Brasília, recém-inaugurada capital do País, em certa medida materializaram essa proposta na década de 1960, inspiradas pela experiência anisiana da Escola Carneiro Ribeiro. Em 1950, as primeiras priorizavam as atividades curriculares, e as segundas, no contraturno, as atividades esportivas e artísticas, buscando o pleno desenvolvimento das crianças.

A Escola-Parque ocupa uma área de $20.544 \mathrm{~m}^{2}$, com um conjunto arquitetônico de três edificações: o bloco principal, conhecido como o Pavilhão de Salas de Aula, o bloco do Auditório e o das Oficinas. O Pavilhão de Salas de Aula destaca-se por características próprias do modernismo arquitetônico: sua forma geometricamente leve, apresenta-se sobre pilotis e grandes vãos, cobertura plana. Os amplos espaços definidos pelos pilotis passaram a ser usados como pátio coberto pelas crianças e a circulação de alunos e funcionários entre os três blocos.

\section{Considerações finais}

Nesta tentativa de aproximar Anísio Teixeira e Darcy Ribeiro trilhamos pela temática da educação integral, condição primordial para um projeto de emancipação social. Orientando-nos por uma "política de liberdade", fizemos com que esses dois intelectuais cruzassem, novamente, um o caminho do outro. Para nós, os resultados foram férteis, porque ao olharmos tanto para a trajetória quanto para seus projetos, conseguimos vislumbrar a possibilidade de uma sociedade autônoma alinhada a um projeto pensado por um, para atender a uma sociedade em pleno processo de crescimento, que ia deixando um lastro de pessoas desatendidas pela escola, e pelo outro, para resgatar o direito social, perdido ao longo da história republicana do pais.

As permanentes relações entre os dois intelectuais fizeram com que Darcy Ribeiro fosse profundamente tocado pela experiência anisiana, a partir do momento em que Anísio Teixeira - como Secretário da Educação e Saúde, nos anos 1950, na Bahia - funda o Centro Educacional Carneiro Ribeiro, que ficaria conhecido como Escola Parque.

$\mathrm{Na}$ tentativa de refletir sobre o que pensaram e fizeram na história educacional, nos pusemos a reconstruir suas trajetórias. Assim, buscamos reconstruir os importantes passos para o amadurecimento de ideias e de alternativas com vistas ao pensamento republicano, de melhorar a qualidade das escolas e da prática pedagógica em nosso país.

Revisitar o debate desses dois ícones do pensamento educacional brasileiro é revitalizar as discussões do Manifesto dos Pioneiros, de 1932 - um marco da história educacional brasileira, em que educadores, pensado $\neg$ res e intelectuais como Fernando de Azevedo, Anísio Teixeira, Lourenço Filho, Almeida Júnior, Paschoal Lemme e tantos outros, figuram entre os seus signatários.

As experiências de educação integral pelas quais passou o Brasil ensaiaram, dentro das condições materiais possíveis, uma aproximação a uma formação humanista moderna. Foi o caso das proposições advindas do Movimento dos Pioneiros da Escola Nova, que se materializaram nas experiências educacionais de Anísio Teixeira, 
no Centro Educacional Carneiro Ribeiro na Bahia, mais tarde, durante a experiência da formação da Cidade de Brasília, com as escolas Classe/Parque e com a própria Universidade de Brasília. Também com os Centros Integrados de Educação Pública (CIEPs) no Rio de Janeiro.

Mudanças demandadas pelos anseios provocados pelo Movimento de 1932, que lançou um manifesto intitulado "A reconstrução educacional no Brasil - ao povo e ao governo", Mais conhecido como Manifesto dos Pioneiros da Escola Nova ${ }^{4}$, rogou pela qualidade da escola pública, inserindo a discussão sobre educação integral.

Recuperar o prejuízo histórico que levou milhões de crianças e jovens a perderem, progressivamente, desde o início do século, seu direito à escola com no mínimo quatro horas diárias, ao longo de sua formação, tornou-se desafio para os dois programas encabeçados por Anísio e Darcy.

Darcy Ribeiro, apaixonado pelas causas sociais, reforçou a tese de que o papel do intelectual implica uma intervenção direta no corpo social. Assim sendo, podemos "defini-lo" como um cidadão paradoxal, extremamente crítico e racional, mas ao mesmo tempo apaixonado e passional.

Dessa forma, não poderíamos deixar distante o pensamento e o trabalho de Anísio que por sua vez influenciou Darcy Ribeiro, transformando-o em um dos intelectuais mais comprometidos, herdeiro ilustre da escola nova. Sua decisão de empunhar a bandeira de renovação da escola pública de qualidade é ressaltada por Bomeny (2003, p.11): "Darcy deixa em suas memórias e correspondências as confissões de afinidade com o educador e filósofo Anísio Teixeira, o programa de democratização educativa e os ideais da Escola Nova”.

No tocante à educação integral, as correntes estudadas têm em comum a defesa intransigente de uma jornada escolar diária de dia inteiro como condição para a formação humana, vista em sua integralidade. O que as diferencia é o nível e a qualidade de seu compromisso de real transformação social, que é impulsionado pelas convicções filosóficas e políticas e sua crença ou não no movimento dialético entre as transformações de base material e as transformações na superestrutura educacional, ou então a negação desta relação em movimento. Esse real, essa totalidade, considerando tanto as coerências quanto os antagonismos de cada forma de perceber a educação integral, é que compõe o conjunto de compreensões e práticas diversas na área.

Para Nunes (2000 ou 1990), a escola primária de hoje no Brasil não é a pensada por Anísio Teixeira, isto é, aquela pela qual ele lutou. A escola de Anísio era formativa desde suas estruturas físicas até a qualificação de seu corpo docente. A imagem da escola mudou muito no Brasil, deixou de ser uma prioridade das políticas públicas.

O ideal de educação primária, pública e de qualidade, propugnada por Anísio Teixeira foi concretizado no Centro Educacional Carneiro Ribeiro. O educador não teve a satisfação de ver seu projeto, tal como por ele foi idealizado, implantado em todo o país, por se tratar de uma escola cara, e, talvez, devido ao fato de que a educação pública nunca tenha sido uma prioridade efetiva das políticas públicas, ou mais ainda, quem sabe Anísio Teixeira tenha nos seduzido à sua própria utopia. 
Ao pensarmos a história, temos a consciência de que ela não se fará isoladamente. As histórias às vezes caminham lado a lado, às vezes se sobrepõem. Escrever a história é compor um quebra-cabeça, onde as peças vão se interligando e revelandonos os seus significados.

É através da reconstrução que o tempo e a memória, os escritos e os ditos se constituem em um cenário para recompor a trajetória de sujeito histórico impregnado de experiências pessoais e coletivas. Halbwachs (1990, p. 54), ao afirmar que toda memória é coletiva, sinaliza para seu atributo mais imediato que é garantir a continuidade do tempo e permitir que a alteridade resista ao tempo que muda e as rupturas, que são o destino da condição humana.

\section{Referências}

BOMENY, H. M. B. Os intelectuais da educação. Rio de Janeiro: Jorge Zahar, 2003, 2. ed.

CALEFI. A. Escola de tempo integral: Reflexões sobre algumas experiências. Dissertação de Mestrado. UNIMEP, Piracicaba: 2003.

CAVALIERE, A. Educação integral: uma nova identidade para a escola brasileira? Educação e Sociedade, Campinas: v. 23, n. 81, dez. 2002.

Entre o pioneirismo e o impasse: a reforma de 1920. Educação e Pesquisa, São Paulo: v. 29, n.1, p. 27-44, jan./jun. 2003.

ÉBOLI, T. Uma experiência de educação integral. [3. ed.]. Rio de Janeiro: Faperj, 1983. Primeira edição, 1969. Disponível em: <http://www.dominiopublico.gov.br/download/texto/ me001840.pdf>. Acesso em: 29 abr. 2015.

HALBWACHS, M. A memória coletiva. Tradução Beatriz Sidou. São Paulo: Centauro, 1990.

JACOBY, R. O fim da utopia: política e cultura na era da apatia. Rio de Janeiro: Record, 2001.

LE GOFF. A história nova. Tradução Eduardo Brandão. São Paulo: Martins Fontes, 1988.

. Historia e memória. Tradução Bernardo Leitão, Campinas: Editora Unicamp, 2003.

. Os Intelectuais na Idade Média. Lisboa: Gradiva, 1984.

NUNES, C. História da educação: espaço de desejo, Em Aberto, Brasília: v. 9, n. 47, p. 37-45, 1990.

Anísio Teixeira: a luta pela escola primária pública no país. In: Anísio Teixeira 1900 -1971 (Provocações em Educação). Campinas: Autores Associados; Bragança Paulista: Universidade São Francisco, 2000.

RIBEIRO, D. Carta a Anísio Teixeira, S1., 28 mar. 1966. Localização do documento: Fundação Getúlio Vargas/CPDOC - Arquivo Anísio Teixeira - ATc 62.04.24/3.

Carta: falas, reflexões, memórias n. 15 - O Novo Livro dos CIEPs / Informe de distribuição restrita do Senador Darcy Ribeiro. Brasília, DF: Gabinete do Senador Darcy Ribeiro, 1995.

Confissões. São Paulo: Companhia das Letras, 1997.

O Livro dos CIEPs. Rio de Janeiro: Bloch, 1986.

Testemunho. São Paulo: Siciliano, 1997.

RIBEIRO, D. Utopia Brasil (Organização Isa Grinspum Ferraz) - São Paulo: Hedra, 2008. 
ROCHA, J. A. L. Anísio em movimento, Brasília: Senado Federal, Conselho Editorial, 2002.

ROCHA, L. M. F e ANTONIAZZI, M. R. F. Anísio Teixeira: educação integral e formação para o trabalho. PEREIRA, E. W. (Org.). MAGALHAES, F. H. (Org.).

ROCHA, L. M. F.; et al. Nas Asas de Brasília: memórias de uma utopia educativa (1956-1964). 1. ed. Brasília: Editora da Universidade de Brasília, 2011.

SIRINELLI, J.-F. Os intelectuais. In: RÉMOND, R. Por uma história política: Rio de Janeiro: Ed. UFRJ/Ed. FGV, 1996.

SMOLKA, A. L. B.; MENEZES, M. C. (Orgs.). Anísio Teixeira 1900-2000: provocações em Educação. Campinas: Associados, 2000.

TEIXEIRA, A. A crise educacional brasileira. Revista Brasileira de Estudos Pedagógicos. Rio de Janeiro, v. 19, n. 50, p. 20-43, abr./jun. 1953.

A educação comum do homem de hoje. In: Educação no Brasil. 2. ed. Atualidades Pedagógicas, v. 132. São Paulo: Ed. Nacional; Brasília: INL/MEC, 1976. p. 362-366.

A escola brasileira e a estabilidade social. In: TEIXEIRA, A. Educação no Brasil. São Paulo: Ed. Nacional/INL - MEC. 1976.

. A Escola Parque da Bahia. Revista Brasileira de Estudos Pedagógicos. Rio de Janeiro, 47 (106): 246-253, abr./jun, 1967.

. A escola pública universal e gratuita. Revista Brasileira de Estudos Pedagógicos. Rio de Janeiro, v. 26, n. 64, out./dez. 1956. p. 3-27.

. Centro Educacional Carneiro Ribeiro. Revista Brasileira de Estudos Pedagógicos. Rio de Janeiro, v. 31, n. 73, p. 78-84, jan./mar. 1959.

Educação é um direito. 3. ed. Rio de Janeiro: Editora UFRJ, 2004.

Educação não é privilégio. 4. ed. São Paulo: Ed. Nacional, 1977.

Educação no Brasil. 2. ed. São Paulo: Ed. Nacional; Brasília: INEP/MEC, 1976.

Estado atual da educação. Revista Brasileira de Estudos Pedagógicos. Rio de Janeiro, 39 (89): p. 8-16, jan./mar, 1963.

. O problema de formação do magistério. Revista Brasileira de Estudos Pedagógicos. Brasília, v. 46, n. 104, p. 278-287, out./dez. 1966.

. Pequena introdução à filosofia da educação. Rio de Janeiro: DP\&A, 2000.

Plano de Construções Escolares de Brasília. Revista Brasileira de Estudos Pedagógicos. Rio de Janeiro, v. 35, n. 81, p. 195-199, jan./mar. 1961.

. Uma experiência de educação primária integral no Brasil. Revista Brasileira de Estu-

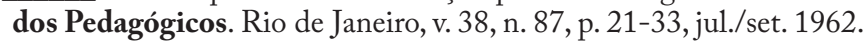

Notas

\footnotetext{
${ }^{1} \mathrm{O}$ tema da educação integral renasce também sob inspiração da Lei no 9.394/ 96, que prevê o aumento progressivo da jornada escolar para o regime de tempo integral (arts. 34 e 87, § 5o) e reconhece e valoriza as iniciativas de instituições que desenvolvem como parceiras da escola, experiências extra-escolares (art. $3^{\circ}$, $\mathrm{X})$. A previsão disposta no artigo 34 - de ampliação da permanência da criança na escola, com a progressiva extensão do horário escolar.
} 
${ }^{2} \mathrm{O}$ estudo vem se desenvolvendo no âmbito do Núcleo de Estudos - Tempos, Espaços e Educação Integral - NEEPHI - e do Núcleo de Estudos e Pesquisas em História da Educação Brasileira - NEPHEB, ambos alocados na Escola de Educação da UNIRIO - Universidade Federal do Estado do Rio de Janeiro, e vinculados ao Programa de Pós-Graduação em Educação - Mestrado (PPGEdu/UNIRIO), da mesma instituição.

${ }^{3}$ São consideradas revoluções burguesas as revoluções inglesas do século XVII (Puritana e Gloriosa) e a Revolução Francesa de 1789.

${ }^{4}$ A Escola Nova, inspirada em grande medida nos avanços do movimento educacional estadunidense e de outros países europeus, teve grande repercussão no Brasil. As ideias foram inspiradas na concepção de aprendizado do aluno por si mesmo, por sua capacidade de observação, de experimentação, tudo isso orientado e estimulado por profissionais da educação que deveriam ser treinados especialmente para esse fim. (BOMENY, 2001, p. 43).

* Assessor do Gabinete do Reitor da Universidade Federal de Santa Maria, Santa Maria, Rio Grande do Sul, Brasil.

Edilson de Souza - Universidade Federal de Santa Maria. Gabinete do Reitor. Av. Roraima n. 1000, Ci de Universitária - Bairro Camobi. CEP: 97105-900. Santa Maria, Rio Grande do Sul, Brasil.

E-mail: edilsonsouza111@gmail.com

Recebido em 07 de maio de 2015

Aprovado em 03 de dezembro de 2015 
